\title{
BANKING 4.0: "THE INFLUENCE OF ARTIFICIAL INTELLIGENCE ON THE BANKING INDUSTRY \& HOW AI IS CHANGING THE FACE OF MODERN DAY BANKS"
}

\author{
Dr. Navleen Kaur \\ Associate Professor, Amity International Business School, \\ Amity University, Uttar Pradesh, Noida, India \\ Supriya Lamba Sahdev \\ Assistant Professor, Amity International Business School, \\ Amity University, Uttar Pradesh, Noida, India \\ Dr. Monika Sharma \\ Amity International Business School, \\ Amity University, Uttar Pradesh, Noida, India

\section{Laraibe Siddiqui} \\ Student, Amity International Business School, \\ Amity University, Uttar Pradesh, Noida, India
}

\begin{abstract}
Artificial intelligence (AI), from time to time called machine intelligence is simulation of human intelligence in machines. It is the intellect exhibited by machines, in contrast to the natural knowledge demonstrated by humans. From Siri to selfdriving cars, AI is progressing at a rapid pace.

Artificial intelligence consists of generally two fundamental ideas. First it involves studying human brains like how their thought process works and secondly it helps representing those processes through machine learning. Artificial Intelligence in finance is more than about chat bots.

Artificial Intelligence has taken over numerous sectors including banking industry. The principal thought behind this investigation was to comprehend the impact of AI on present day banking.

This research mainly focuses on the concept of AI in the field of banking, how it has brought revolutionary changes in banking and its impact on human manpower. As we are aware that humans tend to commit errors, but the world is evolving so does the innovations, there is lack of skilled talents required to handle the automation. Several
\end{abstract}


Banking 4.0: "The Influence of Artificial Intelligence on the Banking Industry \& How AI is Changing the Face of Modern Day Banks"

routine and manual tasks which were earlier performed by the humans are now being replaced by the automated machines with advance technology.

Given that the business is experiencing noteworthy change at a quick pace, this research is a preview of the current applications of AI in the banking industry and how it is changing the face of banking in India.

Key words: artificial intelligence, financial sector, banking 4.0, banking industry, evolution in banking industry, AI in financial sector, machine learning

Cite this Article: Dr. Navleen Kaur, Supriya Lamba Sahdev, Dr. Monika Sharma and Laraibe Siddiqui, Banking 4.0: "The Influence of Artificial Intelligence on the Banking Industry \& How AI is Changing the Face of Modern Day Banks". International Journal of Management, 11 (6), 2020, pp. 577-585.

$\mathrm{http}: / /$ iaeme.com/Home/issue/IJM?Volume $=11 \&$ Issue $=6$

\section{INTRODUCTION}

AI is the simulation of human intelligence which helps to build smarter machines capable of doing human work in a smart way. AI work just like a human brain it can think and make decision with more accuracy rate, based on the data it is being fed.

Artificial intelligence is now becoming more widespread in the current market. It is used in various sectors; banking industry is one among them. Banking industry is using AI in a very innovative way which save plenty of time and money. The banks use algorithms to generate accurate results which in turn help in enhancing customer service and generate better sales performance to deliver profits. AI includes machine learning and profound learning which helps to reduce errors caused by emotional and psychological factors. One of the most important task AI performs is to channelize key information from wide variety of data and draw conclusions.

For instance, IPsoft, the world front-runner in Enterprise AI has built up a humanoid (robot) accomplice Amelia. It is the industry's most human digital AI partner.

When one sees her for the first time it will leave an imprint that she implies business, wearing white oxford shirt underneath a blazer, light hair with a decent attired look. The company acclaims that Amelia's ability to learn, intermingle and progress over time makes her the market's only AI that can fully understand client's requirements and intents. Amelia can be trained to understand words and phrases in more than 100 dialects. She delivers genuine business assistance including lower operating costs, higher customer fulfillment and increased employee competence. When a company hires Amelia (or numerous Amelias) they'll be able to design her to address diversified company needs, roles, and verticals - all according to their specific business strategies and procedures. The humanoid observes, learns, and recalls anything one ask. She can read sentiments and situation during discussions with associates and clients, on any communications network. She can accomplish the tedious work of thousands while assisting with improving the innovativeness and efficiency of her human counter parts.

\section{EVOLUTION}

While we have only recently experienced the implementation of AI, the history of AI dates back to the 1950s, when Alan Turing published a paper on the possibilities of machines with true intelligence. It was just the establishment of Artificial Intelligence as a term, but no application of the case or Artificial Intelligence method was carried out until the late 1990s. Artificial Intelligence speed only picked up after 2011, after major tech giants like Facebook, 
IBM, Microsoft and Google started engaging in Artificial Intelligence and Machine Learning for business applications.

\subsection{Adoption}

Today, AI implementations range from data mining to a variety of methods such as algorithm monitoring, facial detection, optical character recognition. AI is now being applied in a variety of business industries, including advertisement and targeting, accounting, insurance, internet, transportation, aerospace, agriculture and genetics.

In 1990, new technologies focused on work in the AI field, expanding the potential for natural language analysis, image recognition, deep learning, voice recognition and emotions. It was then taken up by a number of start-ups with a view to generating market interest.

\subsection{AI in Financial Services}

There are also a range of improvements in the way communications, customer support, recruiting and asset management take place throughout financial sector. Today, for example, stock investing and finance is all about technical skills and divine luck. Yet in the future, with the aid of sentiment analysis, crowd-sourced data and algorithms, we will be able to handle money in a much different way.

\subsection{Future Aspects}

Not only is the AI revolution limited to the financial sector and banking industry, a variety of other sectors have also experienced the effects of AI. Some of the industry highlights include robotic (automated) distribution of anesthesia for routine treatments, while helping to minimize costs, improved patient support, digital guidance to the introduction of self-driving vehicles. All these would allow the companies to replace boring and tedious work, such as form filling and back-end testing.

\section{WHY AI IN BANKING INDUSTRY?}

- Enormous challenges in the banking sector.

- Thrust for a process-driven operation.

- Initiate self-service in the branches.

- Customer desire to deliver different personalized solutions.

- Build functional efficiencies.

- Escalating the productivity of employees.

- To support focus on productivity and efficiency.

- Visualization to extend human function with the use of robotics tools.

- To minimize the chances of fraud and scam.

- Manage an immense volume of data at record speed and gain valuable insights.

- To carry out effective decision-making.

\section{REVIEW OF LITERATURE}

Christian Catalini, Chris Foster and Ramana Nanda (2018) in their work 'Machine Intelligence vs. Human Judgment in New Venture Finance' study that machine learning models trained to mimic human evaluators performed relative to models trained purely to maximize financial success. They found out that (1) model trained to mimic the picks of humans performed well out-of-sample, implying that humans had a systematic pattern of 

the Face of Modern Day Banks"

early-stage investing that could be identified and replicated; (2) Models trained to maximize success strongly outperformed 'mimic human models' when picking from a common out-ofsample applicant pool, implying that heuristics used by these evaluators were systematically overlooking certain high-potential applications that were identifiable ex-ante; (3) comparing the focus of the two models suggests that the differences arose in part due to human heuristics systematically under-emphasizing more 'cognitively demanding' elements of the applications. Their findings have important implications for the selection and financing of high potential ideas, and more broadly for how Artificial Intelligence can help humans screen and evaluate information in an era of increasing 'information overload'.

Jewandah S (2018, July) in her research paper "How Artificial Intelligence is changing the banking sector - A case study of top four Commercial Indian Banks" studies the areas in which Machine Intelligence is being launched in the banks and applications of AI in principal commercial banks in India. There is advancement in traditional banking and gradually banks are adopting innovative technologies like AI, blockchain, cloud computing but banks are still to reach the stage of AI revolution, human touch is still important. The banking sector in India is discovering the ways through which AI can be incorporated which improve working of banks and improve customer service in the near future.

Andrew Ng (2016) in his research paper "What artificial intelligence can do and can't do right now" discusses the implications of AI on business. He discusses about the automation age, how business is evolving because of robotics and machine learning. AI work requires cautiously picking $\mathrm{A}$ and $\mathrm{B}$ and providing the essential information to help the AI figure out the $\mathrm{A} \rightarrow \mathrm{B}$ relationship. Selecting $\mathrm{A}$ and $\mathrm{B}$ creatively has already revolutionized numerous industries. It is ready to revolutionize many more.

Table 1 Machine Learning

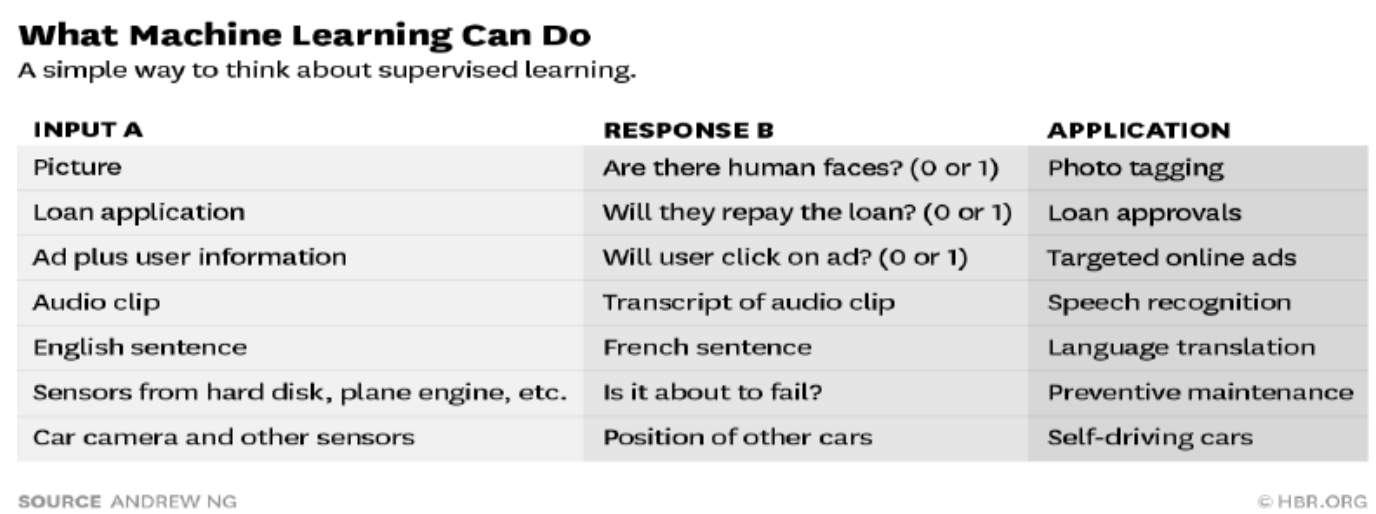

Chan Kok Thim and Eric Seah (2011) in their research paper 'Optimizing portfolio construction using artificial intelligence' intends to improve the viability of Artificial Intelligence utilizing Neural Network $(\mathrm{NN})$ in the real market. This paper summed up the standard Markowitz Theory's Efficient Frontier to emulate and improve the portfolio development and build up a neural system heuristic to better comprehend how Artificial Intelligence can develop ideal portfolio capacity and give yields to all degrees of financial specialists.

Ryoji Kashiwagi (2005) 'Utilization of artificial intelligence in finance' studies that manmade artificial intelligence is presently entering another boom stage, the third in its history, in the wake of a technical advancement known as profound learning. Man-made AI is being used in different structures even in the monetary segment. Money related foundations ought to use man-made consciousness all the more effectively through such methods as open innovation 


\section{RESEARCH METHODOLOGY}

This study used concise and informative analysis methods, as it is mainly a quantitative study and these methods help to gather quantitative data in order to gain a deeper insight into the relationship between different research variables.

The research design is exploratory and descriptive. The type of research undertaken is exploratory as it comprises of in-depth surveys in addition to qualitative and quantitative analysis. It is descriptive research and analytical research as the present state of artificial intelligence is enlightened by using the facts and information already collected.

The research approach to this study was based on a sample used to collect key quantitative data from respondents. The survey method was chosen here to collect data by surveying 112 clients from selected banks. The research instrument used here to gather quantitative data was a formal and closed questionnaire. Quantitative data analysis was conducted using SPSS 21.0 software.

\section{DATA COLLECTION METHODS}

The data gathered is Primary data and Secondary data, which is both quantitative and qualitative data, which was further analyzed in order to draw conclusions and suggestions. Primary data was gathered through a survey on awareness of individuals about use of artificial intelligence in banking sector. A questionnaire was drafted for the survey and random sampling was done. Secondary data collection was done through internet which includes web, e-magazines, research papers, e-books, newspapers etc.

\section{OBJECTIVE}

To study the influence of artificial intelligence in the banking sector \& how AI is changing the face of modern-day banks.

\section{ARTIFICIAL INTELLIGENCE IN BANKING}

The banks cannot afford to wait, to get on their artificial intelligence journey as they have to compete in a future which is packed with innovative and advanced technology.

Drive thru Banking- Drive thru banking allows you to do banking transaction without getting out from car. There is lane where the customer can do transaction through a window. Voice AI system is being developed to replace humans in drive thru banking.

Clinc, an Ann Arbor-based startup that developed voice-powered AI platforms for banking in 2015, ventured into drive-through ordering in July 2018. Its conversational AI innovation can recognize orders if people have language barriers or heavy accents and can make corrections in the conversation.

Bank Stations- Banks can incorporate artificial intelligence at the front office, middle office and back office. The bank stations are a system of self-service terminals that delivers a wide range of value-based e-services to consumers example bill payments, government e-services etc.

Big data is the industry standard today and big data applications in banks are transforming the industry. AI is helping in structuring and sorting the data and banking sector is using the data to improve customer relations. Artificial Intelligence is the future of banking to serve new age customers.

Passbook updation kiosks - The Indian banking industry has been evolving from peopledriven to machines controlled in the past few years. Passbook printing kiosk is an automatic kiosk which enable customers to print their passbooks. Indian banks such as SBI and Bank of 
Banking 4.0: "The Influence of Artificial Intelligence on the Banking Industry \& How AI is Changing the Face of Modern Day Banks"

Baroda have installed this facility in a big way. They have installed self-service passbook kiosks wherein customers can print passbooks on their own.

For instance, Indian Bank SBI has installed Swayam (passbook printing kiosk) that uses barcode technology and allows customers to update their passbooks hassle-free

Although there have been hiring in banks, the nature of skill sets required is changing with spotlight on the front-end talent.

Chatbot-The Intelligent Banking Assistant: Chatbots or virtual assistants are new tools designed to simplify interaction between humans and computer. Chatbots are examples of AI in banking that are replacing the front-desk scenes at the banks. These AI-led machines provide next level digitized and customized interactive experiences to the customers.

Indian Bank SBI has launched chatbot SIA (SBI Intelligent Assistant) which help customers in everyday banking tasks just like bank representatives. It also resolves the questions of NRI customers by providing prompt solutions in the chat box on SBI gateway.

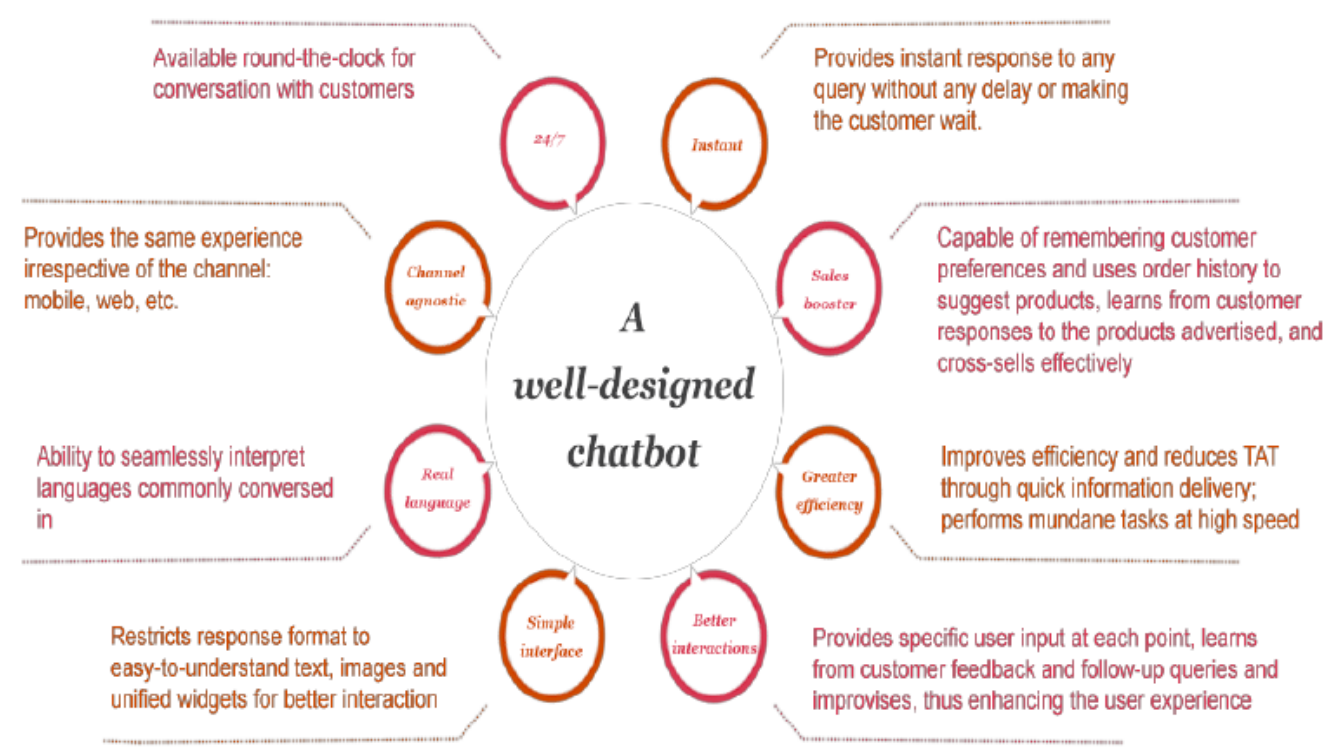

Figure 1 Chatbot

Source:https:/www.pwc.in/consulting/financial-services/fintech/fintech-insights/chatbot-theintelligent-banking-assistant.html

Cash Deposit Machine- The Cash Deposit Machines are self-service terminals which allow to deposit cash at any time. This facility ends the problem of standing in long queues at banks to deposit cash. Banks offer the fastest and most reliable way to deposit cash round the clock. Both state-owned and private banks offer this facility where account balance is credited instantly. Customer will receive a transaction receipt for each successful transaction. Payments can also be made in different accounts using this machine.

ATM Machine Helpline- These help the customers to contact their respective banks in case of emergency these helplines are provided in ATMs. AI has been introduced in ATMs too. The following segments have been introduced in ATMs: Machine learning for cybersecurity in ATMs, machine vision ATM cameras, facial recognition for security and improving customer experience, predictive maintenance of ATM machines, forecasting ATM cash demand. 
Mobile Banking- Mobiles are becoming smarter globally. Millions of people depend vigorously on mobile banking, which means that AI-powered banking mobile apps strongly attract them. Consumers have moved to mobile banking effortlessly. Having personal virtual assistant is very attractive no matter whether it is Siri from Apple or Alexa from Amazon. It has been widely accepted and welcomed by users across the globe.

Mobile apps can readily meet the client's desires. There are intelligent apps that can track the user's behaviors and give them customized tips and insights on savings and expenses. Nowadays every bank offers these services of mobile and text banking. With the use of mobile banking it has become more convenient to do daily transactions such as money transfer, payments etc. Consumers can do better financial planning, can get smart financial advisory, can do efficient and quicker transactions with the advent of artificial intelligence in mobile banking.

Blockchain Technology and Banking: Blockchain is distributed, decentralized and digital ledger. It is digital information (block) stored on public database (chain). Blockchain is used to store encrypted data and Artificial Intelligence is the brain or engine to enable decision making and assists in analysis of data collected.

Most often it is argued that blockchain technology is only beneficial for cryptocurrency industry but that is not true. Blockchain technology visions to solve multiple issues related to digital transactions such as data security, fraud prevention etc. Blockchain is the future of inter-bank transactions, cross border remittances, crypto banking, record storing, KYC, loan syndication, increased transparency to name a few.

AI-based Algorithms and Fraud Detection: AI revolves around algorithms. Machine learning is made up of series of algorithms. Algorithm is a set of rules, instructions or other problem-solving operations to be followed by computers. AI is very effective in finding patterns in real time. It uses additional behavioural indicators to spot suspicious activity and offer suggestions for mitigating risk. For instance, Feedzai, a data science firm, uses algorithms to detect e-commerce fraud.

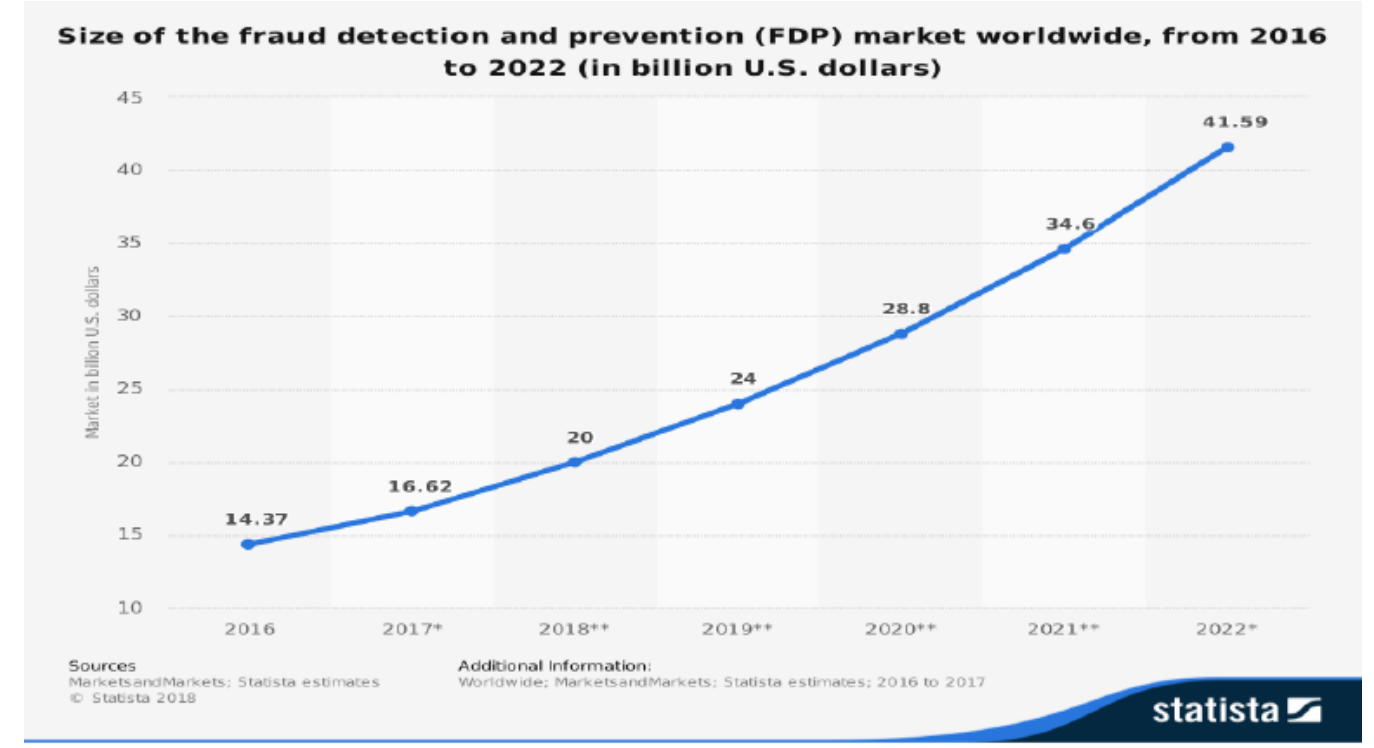

Figure 2 Fraud detection

Fraud detection is one of the fields which has received massive boost in providing accurate and apt results with the intervention of artificial intelligence. Fraud has been the major issue in the financial sector and fraud detection is one of the crucial areas in banking sector where artificial intelligence systems have excelled the most. AI helps to gain a better 
Banking 4.0: "The Influence of Artificial Intelligence on the Banking Industry \& How AI is Changing the Face of Modern Day Banks"

understanding of customer's behavior thus helps in better detection of new and emerging frauds.

An example of successful implementation of data analysis techniques in the banking industry is the FICO Falcon fraud assessment system, which is based on a neural network shell to deployment of sophisticated deep learning based artificial intelligence systems today.

$\mathrm{AI}$ and Machine Learning applications use algorithms to analyze patterns and predictive analytics to block fraudulent transactions thus helping banks to prevent financial frauds. Fraud detection has made considerable progress and is expected to further develop in coming years.

\section{ANALYSIS AND FINDINGS}

This analysis is based on data collected from 112 respondents. Majority of the respondents in mid 20s, 30s and 40s are most impacted by artificial intelligence in banking sector and they also agree that artificial intelligence is valuable and friendly, and they look in for introduction of new innovations in AI from time to time. $71.4 \%$ i.e. 80 people out of 112 think using artificial intelligence in banking is beneficial. $24.1 \%$ i.e. 27 people out of 112 are not sure that using artificial intelligence in banking is beneficial. $4.5 \%$ i.e. 5 people out of 112 don't think that it is beneficial at all. $58.9 \%$ i.e. 99 people out of 112 are taking benefit of automated financial advisor for investing money in the market. $64.3 \%$ i.e. 72 people out of 112 agree that after implementing artificial intelligence in banking system has improved speed of services. $13.4 \%$ i.e. 15 people out of 112 are not sure that it has improved or not. $22.3 \%$ i.e. 25 people don't agree that it has any impact on fast services.

Most of the respondents prefer smart wallets over cash transaction which means people are taking benefits of artificial intelligence. As online fraud is a major issue now days people can easily hack into your account, $81.4 \%$ respondents believe that artificial intelligence can double the security system in banks. $18.6 \%$ people do not fully trust the machines, they need a little bit of human touch and prefer visiting the banks in traditional ways.

\section{CONCLUSIONS}

The world of banking is shifting faster than ever, with Artificial Intelligence (AI) leading the way in bringing in sea change in the banking industry. Various AI technologies have been applied in banking in fields such as core banking, operational performance, customer support and analytics. For AI, banking is no longer just physical branches, but a brand-new world of modern banks. The introduction of new banking services by modern day banks is helping them to grow and expand. Technology is enabling increased penetration of the banking system, increased cost effectiveness and is making small value transactions possible. Effective use of technology has a multiplier effect on growth and development of banks. Hence with the introduction of artificial intelligence, more customers are attracted, and it is helping the banks to grow more. Banks can apply AI to improve the client experience by empowering frictionless, round the clock client association - however AI in banking applications isn't simply restricted to retail banking services. The back and middle office of investment banking and all other money related supervisions are gaining by AI.

\section{REFERENCES}

[1] C Catalini, C Foster, R Nanda (2018) - tuck.dartmouth.edu Machine intelligence vs. human judgement in new venture finance

[2] Chakraborty, C., \& Joseph, A. (2017). Machine learning at central banks. Available at:https://www.bankofengland.co.uk/working-paper/2017/machine-learning-at-centralbanks. 
Dr. Navleen Kaur, Supriya Lamba Sahdev, Dr. Monika Sharma and Laraibe Siddiqui

[3] H. Chen, "Business and Market Intelligence 2.0, Part 2," in IEEE Intelligent Systems, vol. 25, no. 2, pp. 74-82, March-April 2010, doi: 10.1109/MIS.2010.43.

[4] Kaur, N. and Sirohi, R. (2013). Effect of Rupee Depreciation on Common Man. International Journal of Scientific and Research Publications, 3(10).

[5] Ng, A. (2016). Harvard Business Review. Retrieved from https://hbr.org/2016/11/whatartificial-intelligence-can-and-cant-do-right-now

[6] Jewandah, S. (2018). How Artificial Intelligence is changing the banking sector - A case study of top four Commercial Indian Banks. International Journal of Management, Technology and Engineering. Retrieved from http://ijamtes.org/gallery/66.july\%20ijmte\%20-\%20711.pdf

[7] Thim, C.K., \& Seah, E. (2010). Optimizing portfolio construction using artificial intelligence. 5th International Conference on Computer Sciences and Convergence Information Technology, 338-343.

[8] Mukul Anand Pathak, Kshitij Kamlakar, Shwetant Mohapatra, Prof. Uma Nagaraj, (2016) Development of Control Software for Stair Detection n A Mobile Robot Using Artificial Intelligence and Image Processing, International Journal of Computer Engineering and Technology, 7(3), pp. 93-98

[9] T. Dhanabalan, A. Sathish, (2018) Transforming Indian Industries Through Artificial Intelligence and Robotics in Industry 4.0., International Journal of Mechanical Engineering and Technology, 9(10), pp. 835-845.

[10] Sreekanth Reddy Kallem, (2013) Artificial Intelligence in the Movement of Mobile Agent (Robotic), International Journal of Computer Engineering and Technology, 4(6), pp. 394402

[11] https://www.businessinsider.in/finance/news/the-impact-of-artificial-intelligence-in-thebanking-sector-how-ai-is-being-used-in-2020/articleshow/72860899.cms

[12] https://www.enterpriseedges.com/future-artificial-intelligence-banking-sector

[13] https://pxhere.com/en/photo/1449123

[14] https://www.pwc.in/consulting/financial-services/fintech/fintech-insights/chatbot-theintelligent-banking-assistant.html

[15] https://www.analyticsvidhya.com/blog/2017/04/5-ai-applications-in-banking-to-look-outfor-in-next-5-years/

[16] https://hbr.org/2016/11/what-artificial-intelligence-can-and-cant-do-right-now

[17] https://www.cnbctv18.com/ms/future-of-work/article/banking-40-how-humans-willcontinue-to-remain-indispensable-5102111.htm

[18] https://www.livemint.com/Opinion/mwj8mRPsoyXmx1597XKJ8H/How-banks-can-ridethe-artificial-intelligence-wave.html

[19] https://www.fintechnews.org/ai-bakability-10-ways-artificial-intelligence-is-transformingbanking/

[20] https://economictimes.indiatimes.com/industry/banking/finance/banking/sbi-other-banksusing-ai-big-time-to-improve-efficiency-cut-costs/articleshow/64814370.cms?from=mdr

[21] https://emerj.com/ai-sector-overviews/artificial-intelligence-for-atms-6-currentapplications/

[22] https://www.netguru.com/blog/fraud-detection-with-machine-learning-banking

[23] https://www.pragnakalp.com/artificial-intelligence-ai-in-mobile-banking-transformingthe-customer-experience/https://www.disruptordaily.com/blockchain-use-cases-banking/ 